\title{
Function of the Endocannabinoid System in Neurodegenerative Diseases and Cancers
}

\author{
Mario Soliman', Shobha Potlakayala ${ }^{2 *}$, Dhimant Desai ${ }^{3 *}$, Hannah Weeden ${ }^{2}$, Rabab Husain ${ }^{2}$, \\ Nicole Lookfong², Thomas Trite ${ }^{4}$, John Spagnola4, Shantu Amin ${ }^{3}$, Sairam Rudrabhatla2\# \\ ${ }^{1}$ Burrell College of Osteopathic Medicine, Las Cruces, NM, USA \\ ${ }^{2}$ Penn State Harrisburg, Middletown, PA, USA \\ ${ }^{3}$ Departments of Pharmacology, Pennsylvania State University College of Medicine, Hershey, PA, USA \\ ${ }^{4}$ PA Options for Wellness Inc., Harrisburg, PA, USA \\ Email: " svr11@psu.edu
}

How to cite this paper: Soliman, M., Potlakayala, S., Desai, D., Weeden, H., Husain, R., Lookfong, N., Trite, T., Spagnola, J., Amin, S. and Rudrabhatla, S. (2019) Function of the Endocannabinoid System in Neurodegenerative Diseases and Cancers. American Journal of Plant Sciences, 10, 1839-1854.

https://doi.org/10.4236/ajps.2019.1010130

Received: September 4, 2019

Accepted: October 22, 2019

Published: October 25, 2019

Copyright (c) 2019 by author(s) and Scientific Research Publishing Inc. This work is licensed under the Creative Commons Attribution International License (CC BY 4.0).

http://creativecommons.org/licenses/by/4.0/

\begin{abstract}
Neurodegenerative diseases are characterized by progressive degeneration and/or death of neuronal cells and results in a wide array of cognitive impairments and other serious neurological defects. The signaling pathways and definite cause underlying the development of neurodegenerative nerve diseases have not been well defined. There is evidence of mechanisms within the endocannabinoid system that may suggest important pathways involved the progression of neurodegenerative diseases as well as some cancers. The endocannabinoid system is an endogenous ubiquitous neuromodulatory system that plays a critical in the development of the central nervous system (CNS), synaptic plasticity, as well as other primary neuronal functions. The recent identification of various cannabinoid receptors and their endogenous lipid ligands has generated an interest and significant increase in research of the endocannabinoid system and its role in human health and diseases. The Endocannabinoid system possesses essential endogenous receptors-cannabinoid receptors type 1 (CB1R) and type 2 (CB2R)which are involved in mechanisms that contribute to the progression of neurodegenerative diseases and some cancers. In this review, we discuss the role of the endocannabinoid system in various neurodegenerative diseases as well as some cancers, and its promise as a targeted pharmacological therapy for patients of neurodegenerative diseases.
\end{abstract}

\section{Keywords}

Cannabinoid, Endocannabinoid System, Neurodegenerative Disorders, Cancer

${ }^{\star}$ These authors share equal authorship. 


\section{Introduction}

Cannabis sativa, an annual herbaceous flowering plant, contains over 500 different compounds. Cannabinoids are naturally occurring compounds, only 85 of which are characterized as cannabinoids [1]. Amongst the cannabinoid compounds, 9-tetrahydrocannabinol $\left(\Delta^{9}\right.$-THC) is known for its psychoactive effects on the central nervous system (CNS) and peripheral nervous system (PNS0) [2] [3]. $\Delta^{9}$-THC elicits its pharmacological effects by binding to cannabinoid receptors (CBRs), cell membrane receptors that are present in the CNS and PNS and are further classified as $\mathrm{CB} 1 \mathrm{R}$ and $\mathrm{CB} 2 \mathrm{R}$, which are members of the G-protein coupled receptor (GPCR) family [2] [4]. The downstream signaling of the CBRs is key in standard housekeeping functions and plays a substantial role in the endocannabinoid system, a ubiquitous lipid-based retrograde neurotransmitter signaling system that exerts protective pathophysiological conditions in the CNS and PNS [2]. Endogenous CBR ligands, such as $N$-arachidonoyl ethanolamine (AEA) and 2-arachidonoyl glycerol (2-AG), have shown their role in regulating key functions, particularly within the CNS and are termed endocannabinoids [1]. AEA and 2-AG (Figure 1) are endogenous lipid mediators that exert protective pathophysiological conditions, such chronic neurodegenerative and cardiovascular diseases, and play a key role in the endocannabinoid system [5].

CB1R has shown an increased differential expression in human brain, skeletal muscle, liver, and pancreatic islets, which are also known as Langerhans cells [5]. Although CB1R expression is the highest expression in brain and skeletal muscle, $\mathrm{CB} 1 \mathrm{Rb}$ shows higher expression in liver and pancreatic islet cells and plays an important role in metabolic regulatory functions [4]. Compared to CB1R, $\mathrm{CB} 1 \mathrm{Rb}$ has a 33 amino acid deletion at the $\mathrm{N}$-terminus [4].

Although expressed in non-neural cells, such as immune cells, CB1R differential expression is concentration-specific inhibitory and excitatory neurons, $\gamma$ -aminobutyric acid (GABA) - releasing neurons and glutamatergic-releasing neurons, respectively [6]. Activation of the CB1R results in retrograde suppression of neurotransmitter release that can send inhibitory or excitatory signals depending on the location of the CB1R expression in the brain [7]. The heterogonous distribution of CB1R in the CNS allows for the unique pharmacological effects of CB1R agonists to impair cognition, memory, and motor function alteration [7]. Pharmacological CB1R agonist effects have allowed researchers to identify heavily populated CB1R regions within the brain; some of the heavily populated regions include cerebral cortex, hippocampus, lateral caudate putamen, substantia nigra pars reticulata, globus pallidus, entopeduncular nucleus and the molecular layer of the cerebellum [5]. CB1R is mostly found in the CNS as well as in nerve terminals within peripheral tissues including the heart, vas deferens, urinary bladder, and small intestine [2] [5]. Additionally, CB2R can be found in peripheral tissues including the testes and immune-modulating cells.

There are several FDA approved exogenous cannabinoid therapeutic medications, such as Epidiolex, Dronabinol (Marinol'), and Nabilone (Cesamet') [8]. Epidiolex is used in the treatment of Lennox-Gastaut syndrome and Dravet 


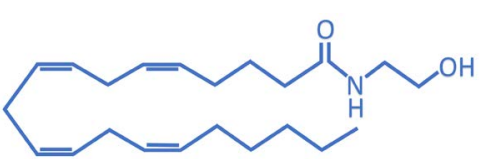

(a)

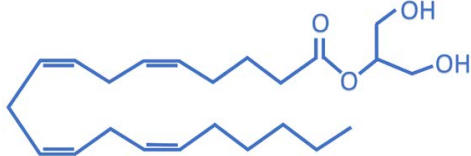

(b)

Figure 1. The chemical structures of the endogenous endocannabinoids compounds (a) anandamide, also known as $\mathrm{N}$-arachidonoylethanolamine (AEA) and (b) 2-Arachidonoylglycerol (2-AG).

syndrome, two rare forms of epilepsy [9] [10] [11]. Dronabinol is used as an anti-emetic for patients with acquired immunodeficiency syndrome (AIDS) undergoing chemotherapy and experiencing loss appetite [8]. Nabilone, synthetic analogue of $\Delta^{9}$-THC, is used by oncologists as a last resort as an anti-emetic in patients undergoing chemotherapy [8]. Other medications, some of which shown in Table 1, acting on CBRs are used to treat a wide array of indications such as multiple sclerosis, anorexia, and neuropathic pain include Bedrocan', Bedrobinol $^{\circ}$, Bediol ${ }^{\circledR}$, Bedica ${ }^{\circ}$, Cesamet, Marinol, and Sativex [5] [8] [12] [13].

The endocannabinoid system and associated endocannabinoid compounds elicit unique retrograde signaling pathways and possess neuroprotective properties that elucidate the strong rationale to further investigate its ability as therapeutic targets in chronic neurodegenerative diseases and cancers.

\section{Chronic Neurodegenerative Diseases: Alzheimer, Post-Traumatic Stress Disorder, Huntington, and Parkinson}

\section{Alzheimer's Disease (AD)}

Alzheimer's disease (AD) is a chronic neurodegenerative disease that presents in patients as short-term memory loss, aphasia, and apraxia [5] [14]. As AD advances, patients develop judgement and language impairment, anxiety, as well as mood and sleep disturbances [14]. Cognitive impairment in AD is associated with cerebral disturbances, particularly in the frontal cortex and hippocampus, regions rich in CB1R. Although the cause of $\mathrm{AD}$ is not well understood, researchers have characterized $\mathrm{AD}$ pathology by the accumulation of $\beta$-amyloid $(\mathrm{A} \beta)$, aggregates of hyperphosphorylated tau proteins or neurofibrillary tangles (NFT's) as well as neuroinflammation that result from hyper-activate glial cells [14]. The discovery of heterogeneous expression of CB1R within the limbic cortex as well as in the hippocampus (the substantia nigra pars reticulata and the globus pallidus) and endocannabinoid compounds has shed light on the role of the endocannabinoid system in patients of $\mathrm{AD}$ [5].

Cannabinoid receptor agonists, including AEA and 2-AG, have shown neuroprotective concentration-dependent inhibition $\mathrm{A} \beta$ induced neurotoxicity in differentiated human teratocarcinoma cell line, NTERA 2/cl-D1 neurons [15]. The $\mathrm{CBR}$ agonists mediate their protective effects on $\mathrm{A} \beta$ induced neurodegeneration by activating the mitogen-activated protein kinase (MAPK) pathway [15]. In 
Table 1. Cannabinoid-based therapies used to treat disorders and/ or symptoms.

\begin{tabular}{|c|c|c|c|c|}
\hline Condition & Cannabinoid-Based Drug & Outcomes for Pain & $\begin{array}{l}\text { Outcomes for Depression and } \\
\text { Anxiety }\end{array}$ & $\begin{array}{l}\text { FDA } \\
\text { Approved }\end{array}$ \\
\hline Lennox-gastaut syndrome & Epidiolex ${ }^{\circledast}$ & $\downarrow$ Pain, epileptic episodes & $\downarrow$ Anxiety & Yes \\
\hline Dravet syndrome & Epidiolex $^{\oplus}$ & $\downarrow$ Pain, epileptic episodes & $\downarrow$ Anxiety & Yes \\
\hline HIV & Marijuana & $\downarrow$ Muscle, nerve pain & $\downarrow$ Anxiety & No \\
\hline Cancer & Nabilone & $\downarrow$ Pain score & $\downarrow$ Overall stress & No \\
\hline Fibromyalgia & Nabilone & $\downarrow$ Pain & $\downarrow$ Anxiety & No \\
\hline Psychiatric disorders & Nabilone & $\downarrow$ Pain & $\begin{array}{l}\downarrow \text { Post-traumatic stress disorder } \\
\text { symptoms }\end{array}$ & No \\
\hline Chronic central neuropathic pain & $\Delta^{9}-\mathrm{THC}$ & $\downarrow$ Pain and pain intensity & $\downarrow$ Anxiety & No \\
\hline Diabetic peripheral neuropathy & Sativex ( $\Delta^{9}$-THC, cannabidiol) & $\downarrow$ Pain & $\uparrow Q u a l i t y$ of life & No \\
\hline
\end{tabular}

another $\mathrm{AD}$ study, effects of $\mathrm{CBR}$ agonists on inhibiting $\mathrm{A} \beta$ fragments were counteracted by a CB1R antagonist, SR141716A, and were unsuccessful in inhibiting $\mathrm{A} \beta$-induced toxicity [15].

Senile plaques, decaying nerve terminals around an $\mathrm{A} \beta$ core, in $\mathrm{AD}$ patients express CB1R and CB2R have shown to have a direct association with markers of microglial activation that results in $\mathrm{A} \beta$-induced neurotoxicity [16]. In pharmaceutical experiments, GPCR and CB1R protein expression are notably decreased in patients with $\mathrm{AD}$ while the nitration of $\mathrm{CB} 1 \mathrm{R}$ and $\mathrm{CB} 2 \mathrm{R}$ proteins are found to be markedly elevated; these findings were evident consequences of microglial activation [16] [17]. Microglial activation-induced learning and memory impairments seen in patients with $\mathrm{AD}$ were induced by amyloid administration and reversed when WIN-55,212-2 (CB1R agonist) was administered to the rats [16].

Remarkably, $\mathrm{A} \beta$-induced microglial activation was prevented by (HU-210, WIN-55,212-2, and JWH-133) in cultured glial cells [5]. Furthermore, JWH-015, a CB2R agonist, inhibited $\mathrm{A} \beta$-induced CD-40 mediated microglial phagocytosis [18]. In addition to targeting CBRs in $\mathrm{AD}$, studies have shown WIN-55,212-2 preferentially targeting non-CBRs in colon, colorectal, and prostate cancer and therapeutically functioned to reduce tumor growth and proliferation [19] [20] [21]. Other studies investigating non-CBR targets in various cancers such as glioma, myeloma, and lung; the drugs cannabidiol, cannabigerol, and methanandamide worked as agonists to induce apoptosis [22]-[28]. Arachidonoyl ethanolamide or anandamide was also shown to be effective against cancers such as neuroblastoma, cervical, and cholangiocarcinoma via a non-CBR mediated mechanism [29]-[34].

2-Arachidonoyl glycerol (2-AG) is a retrograde endocannabinoid messenger that inhibits postsynaptic neurotransmitter release upon presynaptic activation CB1R. Studies have shown that endocannabinoid cellular reuptake inhibitor, VDM11, rescued hippocampal and loss of memory loss retention in mice hippocampi that have been superinfused with $\mathrm{A} \beta$ [35]; findings indicate that increased levels of $2-\mathrm{AG}$ can further promote decaying nerve terminals, particularly around an $\mathrm{A} \beta$ core, in patients with $\mathrm{AD}[35]$. 
In another study, AEA has been upregulated by Notch-1 signaling in cultured cortical neurons exposed to $A \beta$ and in the cortex of aged rats [36]. Interestingly, study findings provide evidence showing that although $A \beta$ increases expression of the endogenous inhibitor of Notch-1, numb (Nb), AEA and 2-AG can reverse and restore the function of the Notch-1 signaling pathway [5] [36]. Anandamide mediates its effects on Notch-1 by upregulating the Nct expression, a component of the integral membrane protein $\gamma$-secretase [36]. In line with previous studies, a research study showed neuroprotective effects of cannabidiol, a non-psychoactive compound in Cannabis sativa, on a PC12 cell line that is derived from a pheochromocytoma of rat adrenal medulla that contain a mixture of neuroblastic and eosinophilic cells; findings suggest that cannabidiol exerted protection against $\beta$-induced ROS production, lipid peroxidation, caspase-3-mediated apoptosis and elevation of the intracellular calcium concentration in PC12 neuronal cells [37].

\section{Post-Traumatic Stress Disorder (PTSD)}

Interestingly, there have been studies that propose a possible relationship between post-traumatic stress disorder (PTSD) and chronic neurogenerative diseases such as dementia [38]. Post-Traumatic Stress Disorder is a trauma-related disorder with intrusive symptoms such as flashbacks or nightmares, avoidance of distressing reminders of the trauma, such as people or places, and persistent negative beliefs and/or expectations of oneself and others. Marked arousal and reactivity such as hypervigilance, difficulty concentrating, reactive angry outbursts with very little or no provocation, and behavior that is self-destructive are also symptoms of PTSD [39]. Having a stronger understanding of the endocannabinoid system aids in finding new forms of therapeutic intervention, which is needed for individuals with PTSD to improve their response to therapy.

One study explained that when an individual is having a flashback, a symptom of PTSD that causes the re-experiencing or re-living of a traumatic event, the pre-frontal cortex (PFC) is what holds the individual in the present and allows them to make logical decisions [40]. But when one's amygdala is overactive, their PFC is inhibited which results in the individual making decisions based on anger and fear from the traumatic event [40] [41]. The dorsolateral prefrontal cortex (dlPFC) controls inhibitory responses, directing attention, thoughts, and actions [40]. The dlPFC regulates the ventromedial prefrontal cortex (vmPFC), which uses mental representations, decision-making, and emotional processing when regulating the amygdala [40]. When the release of catecholamine occurs, it aids in the dysfunction of the PFC, which harms one's cognitive abilities and causes dysfunction of PTSD due to acute stress, decreasing grey matter in the PFC [40] [41] [42]. Individuals who develop PTSD have been shown to have smaller than average hippocampus volumes [43] [44] [45].

The endocannabinoids 2-AG and AEA have a role in buffering stress and regulating it in the brain [46] [47] [48] [49]. However, chronic stress can impair the endocannabinoid system [49]. Impaired endocannabinoid signaling results 
in susceptibility to psychological disorders, such as Anxiety, Major Depressive Disorder, and Post Traumatic Stress Disorder [49] [50] [51] [52]. The endocannabinoids signaling is impaired in the hippocampus of adults and individuals who experienced early life stresses may have an allostatic load in their hippocampus in mice [49] [53]. When newborn mice are separated from their mothers there is a bidirectional change in the hippocampus and amygdala regarding 2-AG and AEA [49]. The mice in adulthood had hindered endocannabinoid signaling in a reduction of both endocannabinoids and CB1 receptors in their hippocampus; however, the endocannabinoids levels in the amygdala were not affected [49]. Researcher's noticed that when exposed to early life stress in mice their PFC's endocannabinoids were not impacted, but the CB1 receptor was downregulated in adolescence and adulthood [49]. Endocannabinoids in the amygdala of mice during their 12 to 14 weeks of development decreased in AEA and increased in 2-AG, which was later stabilized; however, the CB1 receptors were down-regulated in adolescence and adulthood as well [49]. These findings are interesting as well because in animal models when the CB1 receptor is blocked in the amygdala it has been shown to increase anxiety and the fight or flight response in mice [54].

The reason for the decrease in the endocannabinoid signaling in the hippocampus is due to early life stress which can cause the methylation of the promoter sequence $\mathrm{NR} 3 \mathrm{C} 1$ and down-regulate the expression of glucocorticoid receptors in the hippocampus, and this results in glucocorticoid resistance [49] [55] [56]. The glucocorticoid resistance makes it difficult to regulate one's response to stress and recover from it [49] [56].

The hippocampus of a young mouse is impacted by chronic early life stress similar to the effects of chronic stress in the adult hippocampus such as arborization of neurons, reduced dendritic spine densities, and minimal neurogenesis [46] [49] [57]-[62]. The endocannabinoids are fundamental in neuronal plasticity, which is predominant in its development in early life, and when there is an impairment in its function it becomes difficult for someone who experienced early-life stress to adapt to adult stress due to the lack of plasticity [49] [53]. Endocannabinoids have a role in memory formation and extinction is important because the greater the hippocampus volume, the greater the response to contextual modulation of fear extinction, signals that indicate a threat or no threat, in the most efficacious form of therapy which is prolonged exposure therapy [63].

Fatty Acid amide hydrolase (FAAH) is an enzyme which conducts hydrolysis that reduces the amount of AEA [64]. A single nucleotide polymorphism (C385A) in the FAAH gene had noted a result in a reduction PTSD hyperarousal and stress-induced anxiety compared to other PTSD subjects [64]. Researchers have shown that inhibiting the function of FAAH reduces anxiety symptoms by allowing AEA to increase [64]. Stressful events reducing the AEA are believed to be due to corticotropin-releasing hormone (CRH) that increases the production of FAAH [64] [65] [66]. One study found that boosting the 2-AG-CB1R signal- 
ing created resilience to acute chronic stress in mice that were found to be susceptible and hope to aid in new forms of therapy. Removing the CB1 receptor for 2-AG binding increased the anxiety-like behavior for the mice and diminished resilience in chronic stress [54].

\section{Huntington Disease (HD)}

Huntington's disease (HD) or Huntington's chorea is an inherited progressive neurodegenerative disorder with no curative treatment caused by a mutation in the Huntingtin gene $(H t t)$. Patients of HD can present with choreiform or uncontrolled jerky movements, loss of memory, and restlessness. In patients with $\mathrm{HD}$, the Htt gene contains a trinucleotide repeat (cytosine-adenine-guanine, CAG) that is unstable and can vary in length and results in a polyglutamine (polyG) expansion in the N-terminus of Huntington [5] [67].

Increased N-methyl-D-aspartate receptor (NMDAr) activity has been linked with HD and has been shown to play a regulatory role in other medical conditions such as strokes and epilepsy [68]. A study observed mitochondrial toxin-3-nitropropionic (3-NP)-induced striatal alterations within the basal ganglia in rats similar to the alterations observed in the brain of patients with HD; 3-NP was also shown to play in key role in inducing mitochondrial dysfunction and lipid peroxidation which augment the rate of neuronal cell damage [68] [69]. A study by administering WIN-55,212-2, a synthetic CBR agonist that primarily acts on CB1R was able to successfully inhibit the 3-NP-induced neuronal toxicity and damage in rats; this suggests the protective role of $\mathrm{CBR}$ agonists against 3-NP-induced striatal neurotoxicity that is mediated by the dysfunctional NMDAr [68]. Further mechanistic studies of the CBR's regulatory functions are warranted to further investigate the role of the endocannabinoid system in patients with HD.

\section{Parkinson's Disease (PD)}

Parkinson's disease is a neurodegenerative disorder of the CNS that primarily effects motor functions and is the second most common long-term degenerative disorder. The disease is characterized by the slow degeneration of the substantia nigra within the midbrain and degeneration of dopaminergic neurons [70] [71]. Patients of long-term PD start to develop degenerative effects in the extrapyramidal system starting with degeneration of the substantia nigra par compacta followed by striatal alterations to the globus pallidus, a major interconnected nucleus in the forebrain; this results in projection of the basal ganglia into to cortex [71]. Striatal projection neurons serve to directly send neuronal information to the pars reciculata as well as to the lateral globus pallidus indirectly and thus playing a role in the motor deficits seen in patients of PD [5] [71]. Additionally, Lewy bodies, abnormal aggregates of protein, accumulate in residual dopamine neurons [70].

The disease manifest in an ascending process where the lower brain stem is 
affected first, followed by midbrain, and consequently the prefrontal cortex and neocortex [72]. Patients with PD present with a wide array of symptoms depending on the severity and stage of the disease. The irreversible loss of DA-induced striatal functions leads to bradykinesia, impaired gait and mobility, postural instability, resting tremor, rigidity, and secondary effects such as depression and cognitive impairment [71]. Although the direct and indirect connecting pathways of the striatal projection neurons are believed to play a role in a patient's motor impairments, the circuitry and exact connections of these pathways are not well understood.

A study suggests that blockade of CB1R may alleviate motor impairments observed in PD [5]. The study developed in a rat model of PD with affected nigral dopaminergic neurons showed similar neurotoxicity to that of patients of PD, when administered rimonabant, a CB1R antagonist, which partially attenuated hypokinesia [73]. In another study, a cannabinoid CB1R antagonist administered to rats with severe nigral lesions showed enhanced motor asymmetries as well as enhanced dopamine 1 receptor (D1R) function [74]. Levodopa or L-DOPA, unlike dopamine, is a prodrug that is able to cross the protective blood brain barrier and binds to the $\mathrm{D} 1 \mathrm{R}$ and it is the current therapeutic treatments for PD [60] [75]. Increasing sensitivity or the function of D1R using CB1R antagonist can augment the action of L-DOPA [5] [72] [76].

Blockage of CB1R by administration of SR141716A along with D1R (SKF38393) and D2R (quinpirole) agonists into striatum, globus pallidus, and subthalamic nucleus showed reduced motor asymmetry in parkinsonian rats compared to the D1R and D2R alone [77]. In another study, CB1R selective antagonist (1-[7-(2-chlorophenyl)-8-(4-chlorophenyl)-2-methylpyrazolo[1,5-a]-[1,3,5] triazin-4-yl]-3-ethylaminoazetidine-3-carboxylic acid amide benzenesulfonate (CE)) was injected in rhesus monkeys with moderate and severe PD as a monotherapy and in combination with L-DOPA [72]. Results indicated that rhesus monkeys treated with a combination of CE and L-DOPA exhibited increased response to L-DOPA compared to when treated with L-DOPA only. Findings indicate that $\mathrm{CB} 1 \mathrm{R}$ antagonist may enhance the antiparkinsonian actions of dopaminomimetics and allow for lower doses of L-DOPA and thereby reducing any unwanted pharmacological effects [72].

\section{Cancers: Colorectal Cancer (CRC)}

In vitro and in vivo studies provide evidence that suggests efficacy of cannabinoid agonists in reducing tumor growth and proliferation [19]. $\Delta^{9}$-THC has been used as an approved treatment for cancer patients with AIDS experiencing chemotherapy-induced nausea, vomiting, and anorexia [78]. Additionally, cannabinoids have shown to have significant benefit cancer-associated pain and has shown a synergistic effect when combined with opioid analgesics [5]. A recent study has identified synthetic cannabinoid compounds that reduce colorectal cancer (CRC) cell viability mediated by an unknown mechanism [78]. 
Colorectal cancer, the third most common cause of cancer death, is characterized by mutations in the adenomatous polyposis coli (APC), KRAS, and p53 genes [79]. CB1R and CB2R are expressed in human colorectal adenoma and carcinoma [80]. In another study, CB2R activation was found to contribute to the disease progression in $\mathrm{CRC}$ indicating potential use of CB2R antagonist for therapy [81] [82]. Moreover, $\Delta^{9}$-THC was identified as potent RAS-MAPK and PI3K-AKT signaling inhibitor inducing BAD-mediated apoptosis in CRC cells; findings indicate that $\mathrm{CB} 1 \mathrm{R}$ and proapoptotic $\mathrm{BCL}-2$ family member $\mathrm{BAD}$ play a role in regulating the apoptosis in CRC cells [80]. In addition to receptor targets, other cancer-related off-receptor targets have been identified to mediate their effects on cancer by interacting with the endocannabinoid systems and its various components and cannabinoid ligands [19]. Although other cancers-such as lung cancer, colon cancer, and pancreatic cancer-have been identified to interact with the endocannabinoid system, additional mechanistic studies are warranted to further investigate CBR's regulatory functions [5] [19] [83] [84].

\section{Conclusion}

The endocannabinoid system is a complex and ubiquitous cell-signaling system that has not been fully understood. There has been evidence suggesting the role of endocannabinoids, cannabinoid receptors, and other parts of the endocannabinoid system in degenerative diseases and cancers. Researchers have been developing preclinical animal models aimed to study and understand the effects of pharmacological therapeutics on the endocannabinoid system. Pharmacological studies have shown therapeutic strategies that have shown both neuroprotective and symptom-relieving properties in patients with neurodegenerative diseases and certain cancers. There is great promise in understanding the endocannabinoid system for its function as targeted pharmacological therapeutics for neurodegenerative diseases and various cancers.

\section{Acknowledgements}

The corresponding author would like to acknowledge the School of Science, Engineering, and Technology at Penn State Harrisburg for their support.

\section{Author Disclosure Statement}

There are no competing financial interests.

\section{Funding Statement}

The corresponding author acknowledges funding support from Dr. John Mason Jr., Chancellor of Penn State Harrisburg.

\section{Conflicts of Interest}

The authors declare no conflicts of interest regarding the publication of this paper. 


\section{References}

[1] Brenneisen, R. (2007) Chemistry and Analysis of Phytocannabinoids and Other Cannabis Constituents. In: El Sohly, M.A., Ed., Marijuana and the Cannabinoids, Humana Press, Cliftong, 17-49. https://doi.org/10.1007/978-1-59259-947-9_2

[2] Mannucci, C., Navarra, M., Calapai, F., Spagnolo, E., Busardo, F., Cas, R., Calapai, G., et al. (2017) Neurological Aspects of Medical Use of Cannabidiol. CNS \& Neurological Disorders-Drug Targets, 16, 541-553. https://doi.org/10.2174/1871527316666170413114210

[3] Morales, P., Reggio, P.H. and Jagerovic, N. (2017) An Overview on Medicinal Chemistry of Synthetic and Natural Derivatives of Cannabidiol. Frontiers in Pharmacology, 8, 422. https://doi.org/10.3389/fphar.2017.00422

[4] Chanda, D., Neumann, D. and Glatz, J.F.C. (2016) The Endocannabinoid System: Overview of an Emerging Multi-Faceted Therapeutic Target. Prostaglandins, Leukotrienes \& Essential Fatty Acids, 140, 51-56. https://doi.org/10.1016/j.plefa.2018.11.016

[5] Basavarajappa, B.S., Shivakumar, M., Joshi, V. and Subbanna, S. (2017) Endocannabinoid System in Neurodegenerative Disorders. Journal of Neurochemistry, 142, 624-648. https://doi.org/10.1111/jnc.14098

[6] Katona, I., Urbán, G.M., Wallace, M., Ledent, C., Jung, K.M., Piomelli, D., Freund, T.F., et al. (2006) Molecular Composition of the Endocannabinoid System at Glutamatergic Synapses. Journal of Neuroscience, 26, 5628-5637. https://doi.org/10.1523/JNEUROSCI.0309-06.2006

[7] Campion, D., Dumanchin, C., Hannequin, D., Dubois, B., Belliard, S., Puel, M., Frebourg, T., et al. (1999) Early-Onset Autosomal Dominant Alzheimer Disease: Prevalence, Genetic Heterogeneity, and Mutation Spectrum. The American Journal of Human Genetics, 65, 664-670. https://doi.org/10.1086/302553

[8] Smith, L.A., Azariah, F., Lavender, V.T., Stoner, N.S. and Bettiol, S. (2015) Cannabinoids for Nausea and Vomiting in Adults with Cancer Receiving Chemotherapy. Cochrane Database of Systematic Reviews, No. 11, CD009464. https://doi.org/10.1002/14651858.CD009464.pub2

[9] Reddy, D.S. and Golub, V.M. (2016) The Pharmacological Basis of Cannabis Therapy for Epilepsy. Journal of Pharmacology and Experimental Therapeutics, 357, 45-55. https://doi.org/10.1124/jpet.115.230151

[10] Ostendorf, A.P. and Ng, Y.T. (2017) Treatment-Resistant Lennox-Gastaut Syndrome: Therapeutic Trends, Challenges and Future Directions. Neuropsychiatric Disease and Treatment, 13, 1131-1140. https://doi.org/10.2147/NDT.S115996

[11] Devinsky, O., Cilio, M.R., Cross, H., Fernandez-Ruiz, J., French, J., Hill, C., Friedman, D., et al. (2014) Cannabidiol: Pharmacology and Potential Therapeutic Role in Epilepsy and Other Neuropsychiatric Disorders. Epilepsia, 55, 791-802. https://doi.org/10.1111/epi.12631

[12] Gaston, T.E. and Friedman, D. (2017) Pharmacology of Cannabinoids in the Treatment of Epilepsy. Epilepsy \& Behavior, 70, 313-318. https://doi.org/10.1016/j.yebeh.2016.11.016

[13] Huang, W.J., Chen, W.W. and Zhang, X. (2016) Endocannabinoid System: Role in Depression, Reward and Pain Control (Review). Molecular Medicine Reports, 14, 2899-2903. https://doi.org/10.3892/mmr.2016.5585

[14] Nelson, P.T., Alafuzoff, I., Bigio, E.H., Bouras, C., Braak, H., Cairns, N.J., Beach, T.G., et al. (2012) Correlation of Alzheimer Disease Neuropathologic Changes with 
Cognitive Status: A Review of the Literature. Journal of Neuropathology \& Experimental Neurology, 71, 362-381. https://doi.org/10.1097/NEN.0b013e31825018f7

[15] Milton, N.G. (2002) Anandamide and Noladin Ether Prevent Neurotoxicity of the Human Amyloid-Beta Peptide. Neuroscience Letters, 332, 127-130. https://doi.org/10.1016/S0304-3940(02)00936-9

[16] Ramirez, B.G., Blazquez, C., del Pulgar, T.G., Guzman, M. and de Ceballos, M.L. (2005) Prevention of Alzheimer's Disease Pathology by Cannabinoids: Neuroprotection Mediated by Blockade of Microglial Activation. Journal of Neuroscience, 25, 1904-1913. https://doi.org/10.1523/JNEUROSCI.4540-04.2005

[17] Solas, M., Francis, P.T., Franco, R. and Ramirez, M.J. (2013) CB2 Receptor and Amyloid Pathology in Frontal Cortex of Alzheimer's Disease Patients. Neurobiology of Aging, 34, 805-808. https://doi.org/10.1016/j.neurobiolaging.2012.06.005

[18] Ehrhart, J., Obregon, D., Mori, T., Hou, H., Sun, N., Shytle, R.D., et al. (2005) Stimulation of Cannabinoid Receptor 2 (CB2) Suppresses Microglial Activation. Journal of Neuroinflammation, 2, 29. https://doi.org/10.1186/1742-2094-2-29

[19] Soderstrom, K., Soliman, E. and Van Dross, R. (2017) Cannabinoids Modulate Neuronal Activity and Cancer by CB1 and CB2 Receptor-Independent Mechanisms. Frontiers in Pharmacology, 8, 72. https://doi.org/10.3389/fphar.2017.00720

[20] Sreevalsan, S., Joseph, S., Jutooru, I., Chadalapaka, G. and Safe, S.H. (2011) Induction of Apoptosis by Cannabinoids in Prostate and Colon Cancer Cells Is Phosphatase Dependent. Anticancer Research, 31, 3799-3807.

[21] Sreevalsan, S. and Safe, S. (2013) The Cannabinoid WIN 55,212-2 Decreases Specificity Protein Transcription Factors and the Oncogenic Cap Protein eIF4E in Colon Cancer Cells. Molecular Cancer Therapeutics, 12, 2483-2493. https://doi.org/10.1158/1535-7163.MCT-13-0486

[22] Borrelli, F., Pagano, E., Romano, B., Panzera, S., Maiello, F., Coppola, D., Izzo, A.A., et al. (2014) Colon Carcinogenesis Is Inhibited by the TRPM8 Antagonist Cannabigerol, a Cannabis-Derived Non-Psychotropic Cannabinoid. Carcinogenesis, 35, 2787-2797. https://doi.org/10.1093/carcin/bgu205

[23] Nabissi, M., Morelli, M.B., Amantini, C., Liberati, S., Santoni, M., Ricci-Vitiani, L., Santoni, G., et al. (2015) Cannabidiol Stimulates Aml-1a-Dependent Glial Differentiation and Inhibits Glioma Stem-Like Cells Proliferation by Inducing Autophagy in a TRPV2-Dependent Manner. International Journal of Cancer, 137, 1855-1869. https://doi.org/10.1002/ijc.29573

[24] Eichele, K., Weinzierl, U., Ramer, R., Brune, K. and Hinz, B. (2006) R(+)-Methanandamide Elicits a Cyclooxygenase-2-Dependent Mitochondrial Apoptosis Signaling Pathway in Human Neuroglioma Cells. Pharmaceutical Research, 23, 90-94. https://doi.org/10.1007/s11095-005-8815-2

[25] Ramer, R., Heinemann, K., Merkord, J., Rohde, H., Salamon, A., Linnebacher, M. and Hinz, B. (2013) COX-2 and PPAR- $\gamma$ Confer Cannabidiol-Induced Apoptosis of Human Lung Cancer Cells. Molecular Cancer Therapeutics, 12, 69-82. https://doi.org/10.1158/1535-7163.MCT-12-0335

[26] Gardner, B., Zhu, L.X., Sharma, S., Tashkin, D.P. and Dubinett, S.M. (2003) Methanandamide Increases COX-2 Expression and Tumor Growth in Murine Lung Cancer. The FASEB Journal, 17, 2157-2159. https://doi.org/10.1096/fj.03-0254fje

[27] Contassot, E., Wilmotte, R., Tenan, M., Belkouch, M.C., Schnuriger, V., de Tribolet, N., Dietrich, P.Y., et al. (2004) Arachidonylethanolamide Induces Apoptosis of Human Glioma Cells through Vanilloid Receptor-1. Journal of Neuropathology \& Experimental Neurology, 63, 956-963. https://doi.org/10.1093/jnen/63.9.956 
[28] Morelli, M.B., Offidani, M., Alesiani, F., Discepoli, G., Liberati, S., Olivieri, A., Nabissi, M., et al. (2014) The Effects of Cannabidiol and Its Synergism with Bortezomib in Multiple Myeloma Cell Lines. A Role for Transient Receptor Potential Vanilloid Type-2. International Journal of Cancer, 134, 2534-2546. https://doi.org/10.1002/ijc.28591

[29] Patsos, H.A., Hicks, D.J., Dobson, R.R., Greenhough, A., Woodman, N., Lane, J.D., Paraskeva, C., et al. (2005) The Endogenous Cannabinoid, Anandamide, Induces Cell Death in Colorectal Carcinoma Cells: A Possible Role for Cyclooxygenase 2. Gut, 54, 1741-1750. https://doi.org/10.1136/gut.2005.073403

[30] Contassot, E., Tenan, M., Schnüriger, V., Pelte, M.-F. and Dietrich, P.-Y. (2004) Arachidonylethanolamide Induces Apoptosis of Uterine Cervix Cancer Cells via Aberrantly Expressed Vanilloid Receptor-1. Gynecologic Oncology, 93, 182-188. https://doi.org/10.1016/j.ygyno.2003.12.040

[31] Hamtiaux, L., Hansoulle, L., Dauguet, N., Muccioli, G.G., Gallez, B. and Lambert, D.M. (2011) Increasing Antiproliferative Properties of Endocannabinoids in N1E-115 Neuroblastoma Cells through Inhibition of Their Metabolism. PLoS ONE, 6, e26823. https://doi.org/10.1371/journal.pone.0026823

[32] Kuc, C., Jenkins, A. and Van Dross, R.T. (2012) Arachidonoyl Ethanolamide (AEA)-Induced Apoptosis Is Mediated by J-Series Prostaglandins and Is Enhanced by Fatty Acid Amide Hydrolase (FAAH) Blockade. Molecular Carcinogenesis, 51, 139-149. https://doi.org/10.1002/mc.20770

[33] Eichele, K., Ramer, R. and Hinz, B. (2009) R(+)-Methanandamide-Induced Apoptosis of Human Cervical Carcinoma Cells Involves a Cyclooxygenase-2-Dependent Pathway. Pharmaceutical Research, 26, 346-355. https://doi.org/10.1007/s11095-008-9748-3

[34] DeMorrow, S., Glaser, S., Francis, H., Venter, J., Vaculin, B., Vaculin, S. and Alpini, G. (2007) Opposing Actions of Endocannabinoids on Cholangiocarcinoma Growth Recruitment of Fas and Fas Ligand to Lipid Rafts. The Journal of Biological Chemistry, 282, 13098-13113. https://doi.org/10.1074/jbc.M608238200

[35] Mulder, J., Zilberter, M., Pasquare, S.J., Alpar, A., Schulte, G., Ferreira, S.G., Harkany, T., et al. (2011) Molecular Reorganization of Endo-1284 Cannabinoid Signalling in Alzheimer's Disease. Brain, 134, 1041-1060. https://doi.org/10.1093/brain/awr046

[36] Tanveer, R., Gowran, A., Noonan, J., Keating, S.E., Bowie, A.G. and Campbell, V.A. (2012) The Endocannabinoid, Anandamide, Augments Notch-1 Signaling in Cultured Cortical Neurons Exposed to Amyloid-Beta and in the Cortex of Aged Rats. The Journal of Biological Chemistry, 287, 34709-34721. https://doi.org/10.1074/jbc.M112.350678

[37] Iuvone, T., Esposito, G., Esposito, R., Santamaria, R., Di Rosa, M. and Izzo, A.A. (2004) Neuroprotective Effect of Cannabidiol, a Non-Psychoactive Component from Cannabis sativa, on Beta Amyloid-Induced Toxicity in PC12 Cells. Journal of Neurochemistry, 89, 134-141. https://doi.org/10.1111/j.1471-4159.2003.02327.x

[38] Loewenstein, D., Curiel, R. and Raffo, A. (2018) PTSD and Neurodegenerative Disorders. Post-Traumatic Stress Disorder, 93. https://doi.org/10.1093/med/9780190259440.003.0006

[39] American Psychiatric Association (2013) Diagnostic and Statistical Manual of Mental Disorders. 5th Edition, Author, Arlington. https://doi.org/10.1176/appi.books.9780890425596

[40] Arnsten, A., Raskind, M., Taylor, F. and Connor, D. (2015) The Effects of Stress 
Exposure on Prefrontal Cortex: Translating Basic Research into Successful Treatments for Post-Traumatic Stress Disorder. Neurobiology of Stress, 1, 89-99. https://doi.org/10.1016/j.ynstr.2014.10.002

[41] Almli, L.M., Fani, N., Smith, A.K. and Ressler, K.J. (2014) Genetic Approaches to Understanding Post-Traumatic Stress Disorder. International Journal of Neuropsychopharmacology, 17, 355-370. https://doi.org/10.1017/S1461145713001090

[42] Lupien, S., Maheul, F. and Weekes, N. (2005) Glucocorticoids: Effects on Human Cognition. In: Steckler, T., Kalin, N.H. and Reul, J.M.H.M., Eds., Handbook of Stress and the Brain Part 1: The Neurobiology of Stress Techniques in the Behavioral and Neural Sciences, Elsevier Science, Amsterdam, 387-402. https://doi.org/10.1016/S0921-0709(05)80022-7

[43] Koenigs, M., Huey, E.D., Raymont, V., Cheon, B., Solomon, J., Wassermann, E.M. and Grafman, J. (2008) Focal Brain Damage Protects against Post-Traumatic Stress Disorder in Combat Veterans. Nature Neuroscience, 11, 232-237. https://doi.org/10.1038/nn2032

[44] Logue, M.W., van Rooij, S., Dennis, E.L., Davis, S.L., Hayes, J.P., Stevens, J.S., Morey, R.A., et al. (2018) Smaller Hippocampal Volume in Posttraumatic Stress Disorder: A Multisite ENIGMA-PGC Study: Subcortical Volumetry Results from Posttraumatic Stress Disorder Consortia. Biological Psychiatry, 83, 244-253. https://doi.org/10.1016/j.biopsych.2017.09.006

[45] Pitman, R., Rasmusson, A., Koenen, K., Shin, L., Orr, S., Gilbertson, M., Liberzon, I., et al. (2012) Biological Studies of Post-Traumatic Stress Disorder. Nature Reviews Neuroscience, 13, 769-787. https://doi.org/10.1038/nrn3339

[46] Eiland, L. and McEwen, B. (2012) Early Life Stress Followed by Subsequent Adult Chronic Stress Potentiates Anxiety and Blunts Hippocampal Structural Remodeling. Hippocampus, 22, 82-91. https://doi.org/10.1002/hipo.20862

[47] Katona, I. and Freund, T. (2012) Multiple Functions of Endocannabinoid Signaling in the Brain. Annual Review of Neuroscience, 35, 529-558. https://doi.org/10.1146/annurev-neuro-062111-150420

[48] Ohno-Shosaku, T. and Kano, M. (2014) Endocannabinoid-Mediated Retrograde Modulation of Synaptic Transmission. Current Opinion in Neurobiology, 29, 1-8. https://doi.org/10.1016/j.conb.2014.03.017

[49] Hill, M.N., Eiland, L., Lee, T.T.Y., Hillard, C.J. and McEwen, B.S. (2019) Early Life Stress Alters the Developmental Trajectory of Corticolimbic Endocannabinoid Signaling in Male Rats. Neuropharmacology, 146, 154-162. https://doi.org/10.1016/j.neuropharm.2018.11.036

[50] Hill, M.N., Campolongo, P., Yehuda, R. and Patel, S. (2018) Integrating Endocannabinoid Signaling and Cannabinoids into the Biology and Treatment of Posttraumatic Stress Disorder. Neuropsychopharmacology, 43, 80-102. https://doi.org/10.1038/npp.2017.162

[51] Hill, M. and Patel, S. (2013) Translational Evidence for the Involvement of the Endocannabinoid System in Stress-Related Psychiatric Illnesses. Biology of Mood and Anxiety Disorders, 3, 19. https://doi.org/10.1186/2045-5380-3-19

[52] Hillard, C., Weinlander, K. and Stuhr, K. (2012) Contributions of Endocannabinoid Signaling to Psychiatric Disorders in Humans: Genetic and Biochemical Evidence. Neuroscience, 204, 207-229. https://doi.org/10.1016/j.neuroscience.2011.11.020

[53] McEwen, B. (2007) Physiology and Neurobiology of Stress and Adaptation: Central Role of the Brain. Physiological Reviews, 87, 873-904.

https://doi.org/10.1152/physrev.00041.2006 
[54] Bluett, R.J., Báldi, R., Haymer, A., Gaulden, A.D., Hartley, N.D., Parrish, W.P., Patel, S., et al. (2017) Endocannabinoid Signalling Modulates Susceptibility to Traumatic Stress Exposure. Nature Communications, 8, Article No. 14782. https://doi.org/10.1038/ncomms14782

[55] Liu, P. and Nusslock, R. (2018) How Stress Gets under the Skin: Early Life Adversity and Glucocorticoid Receptor Epigenetic Regulation. Current Genomics, 19, 653-664. https://doi.org/10.2174/1389202919666171228164350

[56] Turecki, G. and Meaney, M. (2016) Effects of the Social Environment and Stress on Glucocorticoid Receptor Gene Methylation: A Systematic Review. Biological Psychiatry, 79, 87-96. https://doi.org/10.1016/j.biopsych.2014.11.022

[57] Andersen, S. and Teicher, M. (2004) Delayed Effects of Early Stress on Hippocampal Development. Neuropsychopharmacology, 29, 1988-1993. https://doi.org/10.1038/sj.npp.1300528

[58] Brunson, K.L., Kramár, E., Lin, B., Chen, Y., Colgin, L.L., Yanagihara, T.K., Baram, T.Z., et al. (2005) Mechanisms of Late-Onset Cognitive Decline after Early-Life Stress. Journal of Neuroscience, 25, 9328-9338. https://doi.org/10.1523/JNEUROSCI.2281-05.2005

[59] Ivy, A., Rex, C., Chen, Y., Dubé, C., Maras, P.M., Grigoriadis, D.E., Baram, T.Z., et al. (2010) Hippocampal Dysfunction and Cognitive Impairments Provoked by Chronic Early-Life Stress Involve Excessive Activation of CRH Receptors. Journal of Neuroscience, 30, 13005-13015. https://doi.org/10.1523/JNEUROSCI.1784-10.2010

[60] Karten, Y.J., Olariu, A. and Cameron, H.A. (2005) Stress in Early Life Inhibits Neurogenesis in Adulthood. Trends in Neurosciences, 28, 171-172. https://doi.org/10.1016/j.tins.2005.01.009

[61] Leslie, A.T., Akers, K.G., Krakowski, A.D., Stone, S.S., Sakaguchi, M., Arruda-Carvalho, M. and Frankland, P.W. (2011) Impact of Early Adverse Experience on Complexity of Adult-Generated Neurons. Translational Psychiatry, 1, e35.

https://doi.org/10.1038/tp.2011.38

[62] Wang, X.D., Su, Y.A., Wagner, K.V., Avrabos, C., Scharf, S.H., Hartmann, J., Schmidt, M.V., et al. (2013) Nectin-3 Links CRHR1 Signaling to Stress-Induced Memory Deficits and Spine Loss. Nature Neuroscience, 16, 706-713. https://doi.org/10.1038/nn.3395

[63] Rubin, M., Shvil, E., Papini, S., Chhetry, B.T., Helpman, L., Markowitz, J.C., Neria, Y., et al. (2016) Greater Hippocampal Volume Is Associated with PTSD Treatment Response. Psychiatry Research. Neuroimaging, 252, 36-39. https://doi.org/10.1016/j.pscychresns.2016.05.001

[64] Spagnolo, P.A., Ramchandani, V.A., Schwandt, M.L., Kwako, L.E., George, D.T., Mayo, L.M., Heilig, M., et al. (2016) FAAH Gene Variation Moderates Stress Response and Symptom Severity in Patients with Posttraumatic Stress Disorder and Comorbid Alcohol Dependence. Alcoholism, Clinical and Experimental Research, 40, 2426-2434. https://doi.org/10.1111/acer.13210

[65] Gray, J.M., Vecchiarelli, H.A., Morena, M., Lee, T.T., Hermanson, D.J., Kim, A.B., Hill, M.N., et al. (2015) Corticotropin-Releasing Hormone Drives Anandamide Hydrolysis in the Amygdala to Promote Anxiety. Journal of Neuroscience, 35, 3879-3892. https://doi.org/10.1523/JNEUROSCI.2737-14.2015

[66] Hill, M.N., McLaughlin, R.J., Morrish, A.C., Viau, V., Floresco, S.B., Hillard, C.J. and Gorzalka, B.B. (2009) Suppression of Amygdalar Endocannabinoid Signaling by Stress Contributes to Activation of the Hypothalamic-Pituitary-Adrenal Axis. Neuropsychopharmacology, 34, 2733-2745. https://doi.org/10.1038/npp.2009.114 
[67] Anderson, K.E., van Duijn, E., Craufurd, D., Drazinic, C., Edmondson, M., Goodman, N., Goodman, L.V., et al. (2018) Clinical Management of Neuropsychiatric Symptoms of Huntington Disease: Expert-Based Consensus Guidelines on Agitation, Anxiety, Apathy, Psychosis and Sleep Disorders. Journal of Huntington's Disease, 7, 355-366. https://doi.org/10.3233/JHD-180293

[68] Maya-López, M., Colín-González, A.L., Aguilera, G., de Lima, M.E., Colpo-Ceolin, A., Rangel-López, E., Santamaría, A., et al. (2017) Neuroprotective Effect of WIN55,212-2 against 3-Nitropropionic Acid-Induced Toxicity in the Rat Brain: Involvement of CB1 and NMDA Receptors. American Journal of Translational Research, 9, 261-274.

[69] Díaz-Alonso, J., Paraíso-Luna, J., Navarrete, C., Del Río, C., Cantarero, I., Palomares, B., Muñoz, E., et al. (2016) VCE-003.2, a Novel Cannabigerol Derivative, Enhances Neuronal Progenitor Cell Survival and Alleviates Symptomatology in Murine Models of Huntington's Disease. Scientific Reports, 6, Article No. 29789. https://doi.org/10.1038/srep29789

[70] Kalia, L.V. and Lang, A.E. (2015) Parkinson's Disease. The Lancet, 386, 896-912. https://doi.org/10.1016/S0140-6736(14)61393-3

[71] Schneider, R.B., Iourinets, J. and Richard, I.H. (2017) Parkinson's Disease Psychosis: Presentation, Diagnosis and Management. Neurodegenerative Disease Management, 7, 365-376. https://doi.org/10.2217/nmt-2017-0028

[72] Cao, X., Liang, L., Hadcock, J.R., Iredale, P.A., Griffith, D.A., Menniti, F.S., Papa, S.M., et al. (2007) Blockade of Cannabinoid Type 1 Receptors Augments the Antiparkinsonian Action of Levodopa without Affecting Dyskinesias in 1-Methyl4-Phenyl-1,2,3,6-Tetrahydropyridine-Treated Rhesus Monkeys. Journal of Pharmacology and Experimental Therapeutics, 323, 318-326. https://doi.org/10.1124/jpet.107.125666

[73] González, S., Scorticati, C., García-Arencibia, M., de Miguel, R., Ramos, J.A. and Fernández-Ruiz, J. (2006) Effects of Rimonabant, a Selective Cannabinoid CB1 Receptor Antagonist, in a Rat Model of Parkinson's Disease. Brain Research, 1073-1074, 209-219. https://doi.org/10.1016/j.brainres.2005.12.014

[74] Fernandez-Espejo, E., Caraballo, I., de Fonseca, F.R., El Banoua, F., Ferrer, B., Flores, J.A. and Galan-Rodriguez, B. (2005) Cannabinoid CB1 Antagonists Possess Antiparkinsonian Efficacy Only in Rats with Very Severe Nigral Lesion in Experimental Parkinsonism. Neurobiology of Disease, 18, 591-601. https://doi.org/10.1016/j.nbd.2004.10.015

[75] Tambasco, N., Romoli, M. and Calabresi, P. (2018) Levodopa in Parkinson's Disease: Current Status and Future Developments. Current Neuropharmacology, 16, 1239-1252. https://doi.org/10.2174/1570159X15666170510143821

[76] Maccarrone, M., Gubellini, P., Bari, M., Picconi, B., Battista, N., Centonze, D., Calabresi, P., et al. (2003) Levodopa Treatment Reverses Endocannabinoid System Abnormalities in Experimental Parkinsonism. Journal of Neurochemistry, 85, 1018-1025. https://doi.org/10.1046/j.1471-4159.2003.01759.x

[77] El-Banoua, F., Caraballo, I., Flores, J.A., Galan-Rodriguez, B. and Fernandez-Espejo, E. (2004) Effects on Turning of Microinjections into Basal Ganglia of D(1) and D(2) Dopamine Receptors Agonists and the Cannabinoid CB(1) Antagonist SR141716A in a Rat Parkinson's Model. Neurobiology of Disease, 16, 377-385. https://doi.org/10.1016/j.nbd.2004.03.002

[78] Raup-Konsavage, W.M., Johnson, M., Legare, C.A., Yochum, G.S., Morgan, D.J. and Vrana, K. (2018) Synthetic Cannabinoid Activity against Colorectal Cancer 
Cells. Cannabis and Cannabinoid Research, 3, 272-281.

https://doi.org/10.1089/can.2018.0065

[79] Fearon, E.R. (2011) Molecular Genetics of Colorectal Cancer. Annual Review of Pathology, 6, 479-507. https://doi.org/10.1146/annurev-pathol-011110-130235

[80] Greenhough, A., Patsos, H.A., Williams, A.C. and Paraskeva, C. (2007) The Cannabinoid Delta(9)-Tetrahydrocannabinol Inhibits RAS-MAPK and PI3K-AKT Survival Signalling and Induces BAD-Mediated Apoptosis in Colorectal Cancer Cells. International Journal of Cancer, 121, 2172-2180. https://doi.org/10.1002/ijc.22917

[81] Martínez-Martínez, E., Gómez, I., Martín, P., Sánchez, A., Román, L., Tejerina, E., García, J.M., et al. (2015) Cannabinoids Receptor Type 2, CB2, Expression Correlates with Human Colon Cancer Progression and Predicts Patient Survival. Oncoscience, 2, 131-141. https://doi.org/10.18632/oncoscience.119

[82] Martínez-Martínez, E., Martín-ruiz, A., Martín, P., Calvo, V., Provencio, M. and García, J.M. (2016) CB2 Cannabinoid Receptor Activation Promotes Colon Cancer Progression via AKT/GSK3 $\beta$ Signaling Pathway. Oncotarget, 7, 68781-68791. https://doi.org/10.18632/oncotarget.11968

[83] Keresztes, A. and Streicher, J.M. (2017) Synergistic Interaction of the Cannabinoid and Death Receptor Systems: A Potential Target for Future Cancer Therapies? FEBS Letters, 591, 3235-3251. https://doi.org/10.1002/1873-3468.12863

[84] Ramos-González, J., López-Sánchez, D., Castellanos-Garzón, J.A., de Paz, J.F. and Corchado, J.M. (2017) A CBR Framework with Gradient Boosting Based Feature Selection for Lung Cancer Subtype Classification. Computers in Biology and Medicine, 86, 98-106. https://doi.org/10.1016/j.compbiomed.2017.05.010

\footnotetext{
Abbreviations

CB1R - cannabinoid receptor type 1;

CB2R - cannabinoid receptor type 2;

GABA-gamma-amino butyric acid;

MAPK - mitogen-activated protein kinase;

$\Delta^{9}$-THC-Delta-9-tetrahydrocannabinol;

AEA—arachidonylethanolamide (anandamide);

2-AG-2-arachidonylglycerol;

GPCR-G-protein coupled receptor;

NMDA-N-methyl-D-aspartate;

$\mathrm{NMDAr}-\mathrm{N}$-methyl-D-aspartate receptor.
} 